\title{
The difference of lower and upper surface hardness ratio between LED-activated hybrid composite resin and nano composite resin
}

\author{
Deli Mona*, Mochammad Richata Fadil*, Milly Armilia Andang* \\ *Department of Conservative Dentistry Faculty Of Dentistry Universitas Padjadjaran, Indonesia
}

\section{ABSTRACT}

Introduction: Composite polymerization is a polymer molecule formation from monomeric molecules. To obtain good physical and mechanical properties of composite resin restoration, the dental composite resin must have the possibility of an optimal quantity of its monomer converted to the polymer during the polymerization reaction. The type, size, and content of the fillers in the composite are also essential factors in the polymerization process. A hardness test can be used to indirectly measure the hardness ratio of the upper and lower surfaces of the composite material (relative curing degree). The objective of this study was to analyze the differences in the hardness ratio of the upper and lower surface between LED-activated hybrid composite resin and nano composite resin. Methods: Thirty composite resin samples were randomly selected and divided into 2 groups. Group I was the hybrid composite resin group and Group II was the nano composite resin group. Samples were then formed into discs with a diameter of $6 \mathrm{~mm}$ and a thickness of $2 \mathrm{~mm}$ and polymerized using LCU LED with a light intensity of $800 \mathrm{~mW} / \mathrm{cm} 2$ for 20 seconds. After 24 hours, the upper and lower surfaces of each sample were tested for three testing points using Vickers Hardness Tester. The data were then analyzed using the t-test. Results: The hardness ratio between the upper and lower surfaces (relative curing degree) of the hybrid composite resin and nano composite resin was 0.93 and 0.88 consecutively. Conclusion: There is any difference between the upper and lower surface hardness ratio of LED-activated hybrid composite resin and nano composite resin.

Keywords: Lower and upper surface hardness, LED-activated hybrid resin composite, nano resin composite.

\section{INTRODUCTION}

Development of composite resin as a restorative material is very rapid in the last decade. This is influenced by the increasing need for a more aesthetic and stronger restorative material. The manufacturer of composite resin material has made various efforts to obtain satisfactory physical and mechanical properties, both for anterior and posterior tooth restorations. ${ }^{1,2}$
The most popular composite classification ever introduced by Lutz and Philips ${ }^{3}$ is based on particle size filler consisting of a macrofiller, microfiller, and hybrid composite. ${ }^{3,4}$ Hybrid composite resins are composite macrofiller composites with barium glass filler and then added pyrogenic silica microfiller into the resin matrix. The weakness of the composite hybrid resin is that the composite surface becomes coarse, resulting in a loss of gloss on the surface. ${ }^{4,5,6}$ 
The existence of the defects and deficiencies of composite macrofillers, microfillers, and hybrids, led to the development of composites with nanoscale or nanocomposite particles with adequate physical and mechanical properties as restorative materials, both in the anterior and posterior regions, as well as better esthetics. . $, 5,7^{2}$

The depth of irradiation is directly related to the size, particle type and amount of filler. Nanocomposite resins have smaller particles than microfillers that spread more light, so for the polymerization, it takes longer. ${ }^{8}$ Inadequate polymerization will reduce hardness, strength and colour stability and increase water absorption. ${ }^{9,10}$

Hardness tests are usually done by measuring the hardness at the upper and lower of the specimen. According to Koupis et al. ${ }^{11}$, to know the perfection of the irradiation results against the composite resin then compared the hardness between the lower surface with the upper surface called the relative curing degree of the composite resin material. The relative curing degree (RCD) is the level of hardness of the lower surface against the upper surface hardness. ${ }^{11,12}$

To produce optimal polymerization requires a ray of considerable intensity (at least $300 \mathrm{~mW} /$ $\mathrm{cm} 2$ ) and an appropriate wavelength (400-510 $\mathrm{nm}$ ). A light-emitting diode (LED) is one of the most popular light cure unit (LCU). The LED has a wavelength corresponding to the camphorquinone photoinitiator absorption spectrum, as a commonly used photoinitiator. ${ }^{7}$

Some methods used for hardness tests include Brinell, Knoop, Vickers, and Rockwell. Vickers hard-ness test is a hardness test using pyramid diamond indenter with an angle of $136^{\circ}$ to the surface of the material with a particular time and load to indent. ${ }^{13,14}$ Vickers hardness is widely used because the technique is simple, widespread, and the results can be trusted. ${ }^{15}$ Low hardness values indicate the material is soft and vice versa. ${ }^{16}$ This research was aimed to analyze the differences in the hardness ratio of the upper and lower surface between LED-activated hybrid composite resin and nanocomposite resin.

\section{METHODS}

This research was an experimental in-vitro. Population in this research was hybrid composite resin material (Z250) and nano type composite resin (Z $350 \mathrm{XT}$ ) from $3 \mathrm{M}$ ESPE. As many as 30 pieces of composite resin, disc-shaped specimens with a diameter of $6 \mathrm{~mm}$ and a thickness of 2 $\mathrm{mm}$, was prepared. The sample was divided into 2 groups, and each group consists of 15 samples. The research material included a hybrid composite resin patch material of a nanocomposite resin fill material. Research tools used were as follows: (1) Sonde, (2) Tweezers, (3) Excavators, (4) Plastic instrument for composite resin (stopper, spatel), (5) Metal mould for printing sample $\mathrm{mW} / \mathrm{cm} 2$, (7) Vickers Hardness Tester (Leco $®$, Japan), (8) Light intensity gauge (Hilux ${ }^{\circledR}$, Benlioglu Dental. Inc), (9) Markers, (10) Celluloid strips.

Samples were made by using disc-shaped metal moulds of $6 \mathrm{~mm}$ in size and $2 \mathrm{~mm}$ in thickness. The centre of the mould is split in two, to facilitate the release of the sample. The base of the mould is coated with celluloid strips to obtain a smooth, smooth surface. Samples were made of 30 pieces divided into two groups. Group I is a hybrid composite resin, and Group II is nanocomposite resins.

The sample to be tested was stored in a separate container according to the group, immersed in artificial saliva and included in the incubator at a temperature of $36.5^{\circ} \mathrm{C}$ for $24 \mathrm{~h}$. The hardness test on each sample was performed on the top and bottom fields of the sample. Each field was carried out in 3 points, so each sample was carried out in 6 points. Testing was according to the group and serial number.

The sample test started with the sample of Group 1 with sequence number 1 . The sample was marked with a marker on the area to be tested. Each three-point surface (test point 1, 2, 3) was made to ease the determination of the point to be tested. The sample was placed on the Vickers hardness test table, then being set with a stapler to stabilise the sample. The tool pointer was directed to the tested point with the help of a microscope on the Vickers Hardness tester. The test button was activated; the test result would be seen on the screen as the test point 1 serial number 1 group 1 . Next, the pointer was directed to the test point 2; then the measurement was done as at test point 1 , as well as the test point 3 . The test ended at the test point 3 serial numbers 10 Group II. 


\section{RESULTS}

The difference test between the lower and upper surface hardness ratios between hybrid composite resins and nanocomposite resins using LED light activation were performed on samples made with special moulds. Total numbers of samples were 30 pieces. The samples were divided into 2 groups, each group consisted of 15 pieces. Group I consisted of hybrid composite resins, and Group II was consisted of nano composite resins. The tests were performed on the upper and lower surfaces of each sample, each of which was conducted by three adjacent test points. Hardness testing of each sample was carried out with the Vickers Hardness Test. Each sample was tested and recorded, then analyzed statistically. The statistical analysis used was a t-test which aimed to determine whether there was a difference between the lower and upper surface hardness ratio between hybrid composite resins and nanoactivated composite resin. Test results can be seen in Table 1.

From Table 1 can be seen that the upper surface hardness value of Group I was 54.57 VHN, and the lower surface hardness was $50.94 \mathrm{VHN}$. The upper surface hardness level of Group II was

Table 1. Data of hybrid and nano-composite (HVN)

\begin{tabular}{|c|c|c|c|c|}
\hline \multirow[b]{2}{*}{ No } & \multicolumn{2}{|c|}{ Hybrid } & \multicolumn{2}{|c|}{ Nano } \\
\hline & Upper & Lower & Upper & Lower \\
\hline 1 & 57.00 & 54.67 & 47.93 & 45.70 \\
\hline 2 & 60.67 & 53.57 & 52.10 & 47.27 \\
\hline 3 & 53.00 & 50.80 & 50.97 & 47.13 \\
\hline 4 & 55.97 & 53.60 & 51.47 & 47.47 \\
\hline 5 & 50.70 & 50.40 & 55.47 & 41.85 \\
\hline 6 & 57.37 & 55.80 & 40.83 & 34.87 \\
\hline 7 & 53.50 & 51.63 & 48.70 & 44.87 \\
\hline 8 & 52.33 & 49.38 & 51.63 & 41.83 \\
\hline 9 & 53.67 & 45.47 & 51.07 & 48.23 \\
\hline 10 & 52.33 & 52.23 & 42.30 & 40.97 \\
\hline 11 & 50.13 & 46.03 & 50.23 & 46.37 \\
\hline 12 & 55.57 & 46.03 & 57.77 & 48.17 \\
\hline 13 & 53.80 & 47.03 & 47.03 & 40.53 \\
\hline 14 & 57.70 & 54.83 & 51.13 & 40.27 \\
\hline 15 & 55.70 & 52.33 & 62.30 & 52.93 \\
\hline $\begin{array}{c}\text { Average } \\
\text { (VHN) }\end{array}$ & 54.57 & 50.94 & 50.73 & 44.56 \\
\hline
\end{tabular}

Notes: VHN= Vicker Hardness Number $\left(\mathrm{kgf} / \mathrm{mm}^{2}\right)$
50.73 VHN, and the lower surface hardness was 44.56 VHN. Table 1 also shows that the average difference between the hardness of the upper and lower surface between both groups was statistically significant. The average difference between the upper and lower surface in Group I (hybrid) was 3.63, whereas in Group II (nano) was 6.17.

The data from Table 1 then tested for the similarity using student t-test statistics with the following results: the $\mathrm{t}$-count value was 4.90 in Group I, and 6.56 in Group II, with both values were higher than the t-table which (2.14), with the significance level of $99 \%$. This result indicated a significant difference in the hardness between

Table 2. Analysis of the surface hardness similarity test on the upper and lower surface of Group I and II

\begin{tabular}{ccc}
\hline Mean & $\begin{array}{c}\text { Group I } \\
\text { (hybrid) }\end{array}$ & $\begin{array}{c}\text { Group II } \\
\text { (nano) }\end{array}$ \\
\hline $\begin{array}{c}\text { Difference } \\
\text { between lower }\end{array}$ & 3.63 & 6.17 \\
and upper surface & & \\
Std & 2.87 & 3.64 \\
$N$ & 15 & 15 \\
t-count & 4.90 & 6.56 \\
p-value & 0.002 & $6.35 \mathrm{E}-06$ \\
\hline
\end{tabular}

Table 3.Result of lower-upper surface hardness ratio test

\begin{tabular}{ccc}
\hline No & \multicolumn{2}{c}{ Ratio } \\
Group I & $\begin{array}{c}\text { Group II } \\
\text { (nybrid) }\end{array}$ \\
\hline 1 & 0.96 & 0.95 \\
2 & 0.88 & 0.91 \\
3 & 0.96 & 0.92 \\
4 & 0.96 & 0.92 \\
5 & 0.99 & 0.75 \\
6 & 0.97 & 0.85 \\
7 & 0.97 & 0.92 \\
8 & 0.96 & 0.81 \\
9 & 0.85 & 0.94 \\
10 & 0.99 & 0.97 \\
11 & 0.92 & 0.92 \\
12 & 0.83 & 0.83 \\
13 & 0.88 & 0.86 \\
14 & 0.95 & 0.79 \\
15 & 0.94 & 0.85 \\
\hline Average & 0.93 & 0.88 \\
\hline
\end{tabular}


the upper and lower surfaces of each group.

Table 3 shows that the average value of the lower and upper surface hardness ratio in Group I was 0.93 , and the hardness of the baseline surface ratios in Group II was 0.88 . The t-test was used to determine whether there was difference of ratio between Group I (hybrid) with Group II (nano), with the results presented in Table 4.

Table 4 shows the analysis of lower and upper hardness surface ratio which was 24.7, higher than the t-table which was 2.14, thus the result was significant. This result showed a

Table 4. Analysis of similarity test for lower-upper surface hardness ratio between Group I and II

\begin{tabular}{|c|c|c|}
\hline $\begin{array}{c}\text { Hardness ratio } \\
\text { Lower-upper surface }\end{array}$ & $\begin{array}{l}\text { Group I } \\
\text { (Hybrid) }\end{array}$ & $\begin{array}{l}\text { Group II } \\
\text { (Nano) }\end{array}$ \\
\hline Mean & 0.93 & 0.88 \\
\hline Std & 0.051 & 0.064 \\
\hline$N$ & 15 & 15 \\
\hline $\mathrm{t}$-count & \multicolumn{2}{|c|}{24.7} \\
\hline$p$-value & \multicolumn{2}{|c|}{0.099} \\
\hline
\end{tabular}

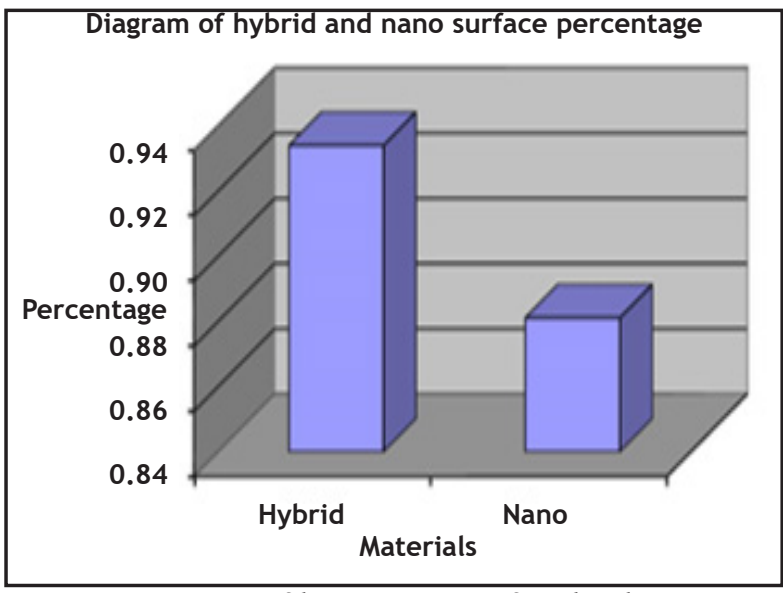

Figure 1. Diagram of lower-upper surface hardness ratio between composite hybrids and nanocomposites

significant difference in the ratio of the lower and upper surface hardness between Group I and Group II. The lower-upper hardness ratio between Group I and Group II is visualized in Figure 1.

\section{DISCUSSION}

The results showed that Group I consisted of hybrid composites resin produced an average surface hardness of $54.57 \mathrm{VHN}$, while in the lower surface was 50.73 VHN. Group II consisted of nanocomposite resin produced an average surface hardness of 50.94 VHN and a lower surface of
44.56 VHN.

The results showed that the upper surface hardness of the hybrid composite resin was higher than the lower hardness. Similarly, in nanocomposite resins, the upper surface hardness was higher than the lower surface. The decrease in the hardness value of the two types of composites tested was due to a decrease in the intensity of light received at the lower surface of the two composite materials in this study. The decrease in the hardness value of the lower surface of the composite material is closely related to the distance of the light source from the composite surface. This difference can be caused by the intensity of the light will decrease as the light passes through the thickness of the composite; the light will be absorbed, propagated and reflected by the filler particles. The spread of these rays causes the effectiveness of the polymerisation to be reduced. This result was consistent with the statement from Albers ${ }^{17}$, which suggested that the composite hardness will decrease as the composite depth increases.

The difference between upper and lower surface hardness between the hybrid composite resin and the nanocomposite resin is due to the filler composition present in the composite material. Hybrid composite resins have two types of filler materials: colloidal silica and glass particles whereas nanocomposite resins have a silica/zirconia ( $\mathrm{Si} / \mathrm{Zr}$ ) filler that has more opaque properties than silica-containing fillers, making it more difficult for light to penetrate the composite materials. According to Uctasli et al.18, penetration of light through the Si/Zr filler is more complicated than composite containing filler or glass. ${ }^{18}$

Apart from different filler types, hybrid composite resins also have higher molecular weight fillers than nanocomposite resins. Fillers of high molecular weight and density tend to absorb more light because of the refractive index of a material. The size of the filler particles also affects the depth of light penetration received by the composite resin material. The hybrid composite has $0.01-3.5 \mu \mathrm{m}$ filler particle size, whereas nanoscale composite particle size ranges from 0.1 to $100 \mathrm{~nm}(1$ nanometer $=1 / 1000 \mu \mathrm{m})$. The smaller the particle size of the filler, the larger the surface area and the beam difference 
will be higher; thus, the intensity will decrease. The decrease in the intensity of the rays will affect the composite hardness. ${ }^{18}$

In this study, the hardness ratio of the lower and upper surface reflects the relative curing degree (RCD) for both types of different composite materials. The lower hardness ratio of hybrid composites was higher (0.93) than the hardness of the lower and upper surface of the nanocomposite $(0.88)$. It proves that RCD composite hybrid composite resins are better than composite nano RCDs, and this difference is significant statistically. It is also following the research conducted by Musanje et al. ${ }^{19}$, which discovered that hybrid composite resin RCDs are better than nanocomposite resins. According to Koupis et al. ${ }^{11}$ and Pires et al. ${ }^{20}$, with a $2 \mathrm{~mm}$ composite thickness, adequate polymerisation can be achieved, which means the relative curing degree is higher than $0.80 .{ }^{11,20}$ From this study, both types of composite materials were included in the category.

The intensity of light received by the composite material will decrease as the thickness of the restoration increases. The thickness of the restoration material will also cause the attenuation of the rays to achieve optimal polymerisation, for which a layer-by-layer technique with a maximum restoration thickness of $2 \mathrm{~mm}$ for each layer is recommended for clinical use.

The exposure time used in this study was 20 seconds, according to the manufacturer's instructions of the used light equipment. According to Peris et al..$^{21}$, the 20-second exposure time using LEDs is adequate for the polymerisation of composite materials, since LEDs have a specific pattern of light emission equal to the absorption of camphorquinone as photo activators of composite resin material. ${ }^{21}$ Lie et al. ${ }^{22}$ also stated that one of the strategies to produce an effective polymerisation is by using a source of light that has a wavelength similar to the photo activator, which is a camphorquinone. ${ }^{22}$

\section{CONCLUSION}

There is any difference between the upper and lower surface hardness ratio of LED-activated hybrid composite resin and nano composite resin.

\section{REFERENCES}

1. de Souza FB, Guimaraes RP, Silva CH. A clinical of packable and microhybrid resin composite restorations: one-year report. Quintessence Int. 2005;36(1):41-8.

2. Bona ÁD, Rosa V, Cecchetti D. Influence of shade and irradiation time on the hardness of composite resins. Braz Dent J. 2007;18(3):2314.

3. Lutz F, Phillips RW. A classification and evaluation of composite resin systems. J Prosthet Dent. 1983;50(4):480-8.

4. Hervás-García A, Martínez-Lozano MA, Cabanes-Vila J, Barjau-Escribano A, Fos-Galve P. Composite resins. A review of the materials and clinical indications. Med Oral Patol Oral Cir Bucal. 2006;11(2):E215-20.

5. Mitra SB, Wu D, Holmes BN. An application of nanotechnology in advanced dental materials. J Am Dent Assoc. 2003;134(10):1382-90.

6. $3 \mathrm{M}$ Dental Products Laboratory, Filtek Ultimate Universal Restorative System: Technical Product Profile; U.S.A. 2010.

7. Powers JM. Craig's Restorative Dental Materials. $12^{\text {th }}$ ed. St. Louis: Mosby-Elsevier; 2006. pp. 64-5, 79-82, 190-200, 201-3.

8. Craig RG, Powers JM, Wataha JC. Dental materials: properties and manipulation. $8^{\text {th }}$ ed. St. Louis: Mosby; 2004. pp. 29, 66-77.

9. Jandt KD, Al-Jasser AM, Al-Ateeq K, Vowles RW, Allen GC. Mechanical properties and radiopacity of experimental glass-silicametal hybrid composites. Dent Mater. 2002;18(6):429-35.

10. Barghi N, Berry T, Hatton C. Evaluating Intensity Output of Curing Lights in Private Dental Offices. J Am Dent Assoc. 1994;125(7):992-6.

11. Koupis NS, Martens LC, Verbeeck RM. Relative curing degree of polyacid-modified and conventional resin composites determined by surface Knoop hardness. Dent Mater. 2006;22(11):1045-50.

12. Cohen M. Statistical estimation of resin composite polymerization sufficiency using microhardness. Dent Mater. 2004;20(2):15866.

13. Anusavice KJ. Phillip's science of dental material. $12^{\text {th }}$ ed. St. Louis: Saunders-Elsevier; 
2003. p.400-36.

14. Van Noort R. Introduction to dental material. $3^{\text {rd }}$ ed. St. Louis: Mosby-Elsevier; 2007.

15. Marghalani HY. Post-irradiation Vickers microhardness development of novel resin composites. Mater Res. 2010;13(1):81-7.

16. McCabe JF, Walls AWG. Applied dental materials. $9^{\text {th }}$ ed. Oxford: Blackwell; 2008. pp. 13, 201-5.

17. Albers HF. Tooth-Colored Restorative, Principles and Technique. $9^{\text {th }}$ ed. Beijing: PMPH-USA; 2002. p. 127-53.

18. Uctasli S, Tezvergil A, Lassila L, Vallittu P. The degree of conversion of fiber-reinforced composites polymerized using different lightcuring sources. Dent Mater. 2005;21(5):469-
75.

19. Musanje L, Darvell B. Curing-light attenuation in filled-resin restorative materials. Dent Mater. 2006;22(9):804-17.

20. Pires JA, Cvitko E, Denehy GE, Swift EJ Jr. Effects of curing tip distance on light intensity and composite resin microhardness. Quintessence Int. 1993;24(7): 517-21.

21. Peris $A R$, Mitsui $F H$, Amaral $C M$, Ambrosano GM, Pimenta LA. The effect of composite type on microhardness when using QTH or LED. Oper Dent. 2005;30(5):649-54.

22. Lie N, Felten K, Trixner K, Hickel R, Kunzelman $\mathrm{KH}$. Shrinkage behaviour of resin-based composite irradiated with modern curing units. Dent Mater. 2005;21:483-9. 